\title{
A Study on the Effect of Elastic Deformation on the Performance of Dynamic Pressure Oil Film Bearing of the Ships
}

\author{
Chao Liu ${ }^{1}$ and Fan-Chun $\mathrm{Li}^{*}, 2$ \\ ${ }^{I}$ Marine Engineering College, Dalian Maritime University, Dalian, 116026, China \\ ${ }^{2}$ Transportation Equipment and Marine Engineering, Dalian Maritime University, China
}

\begin{abstract}
Dynamic pressure oil film bearing is an important mechanical component of the ship. With the development of large-sized ships, their dynamic pressure oil films often run at high speed and under heavy load generating high oil film pressure. In addition, due to the increased use of thin walled bearing shell with materials of low elastic modulus, the elastic deformation of the bearing shell which is in dynamic pressure oil film bearing cannot be ignored. During computation, if the effect of elastic deformation on the performance of dynamic pressure oil film bearing is ignored as is usually the practice, the difference between the theoretical and the actual results will be enormous. Therefore, this article has taken the effect of bearing shell's elastic deformation on bearing performance as the research target. A coupling algorithm program in Matlab is written to simulate and solve the oil film bearing dynamic pressure lubrication theory, considering elastic deformation of bearing shell in a way that is more aligned with the actual working conditions. A comparison is conducted between the above results and the results with no consideration of elastic deformation and the process and regularity of the effect of elastic deformation and other factors on the performance of oil film bearing shell in operation under dynamic lubrication are analyzed. Therefore, more accurate theoretical basis can be provided for the design and fault diagnosis of dynamic pressure oil film bearing of the ships.
\end{abstract}

Keywords: Coupling algorithm, dynamic pressure oil film bearing, elastic deformation, fault diagnosis, oil film pressure, ship.

\section{INTRODUCTION}

The dynamic pressure oil film bearing of the ship is a kind of sliding bearing. During work, with relative motions of the journal and bearing, pressure is generated in the fluid lubrication film between the friction surfaces of the two solids. The film bears the external load and prevents the journal and bearing from touching each other, thereby reducing the frictional resistance and protecting the solid surfaces [1]. This dynamic pressure phenomenon was first observed by B. Tower when he lubricated the machinery and then O. Reynolds explained this phenomenon from dynamic pressure lubrication mechanism and derived the differential equation to describe the pressure distribution of lubrication film [2], known as Reynolds equation. Since then, the primeval basis of hydrodynamic lubrication theory has been laid.

The fluid between the journal and the bearing can prevent direct contact of the two parts but the generated oil film pressure becomes the new load imposed on them. It causes the deformation of the bearing and the bearing shell as well as further changes the pressure distribution of oil film and affects the bearing capacity of the bearing [3]. Due to the complexity of the problem and the restriction of computational power, most of the researches have ignored deformation. For general oil film bearings of light load and low speed, the simplified results can well match with the

*Address correspondence to this author at the Marine Engineering College, Dalian Maritime University, Dalian, 116026, China;

Tel: 18940813802; Fax: 116026; E-mail: dmuhy@126.com actual experimental results [4]. But ultimately, this simplification is not accurate enough, especially for the bearings of large ships. When the bearings run under high speed and heavy load, the deformation of bearing shell caused by oil film pressure is very large, and the calculation can be highly inaccurate if the deformation is ignored at this time [5-7]. This problem has attracted the attention of many scholars. In $1960 \mathrm{~s}, \mathrm{H}$. D. Conway and H. C. Lee [8] simplified the elastic deformation of bearing shell with elastic displacement equation assumed by Winkler and studied the surface elastic displacement effect of thin cylindrical radial bearing shell which were installed in rigid bearing block. In 1980s, American scholar Dacheng Sun [9] proposed special discussions on surface deformation effect. Researches on this issue in China started in the early 80s. When Guankun Zhang and Hong Zhong were studying dynamic-static bearing, they found that sometimes the static oil supply pressure could reach $100 \mathrm{MPa}$; the average pressure was $17 \mathrm{MPa}$ and might even reach $23 \mathrm{MPa}$. In this case, the elastic deformation of the bearing must be taken into consideration, which led them to study this problem. Zhiwen Suo [10] and other scholars of Xi'an Jiaotong University discussed the use of weighted residual methodbased finite element analysis in elastic hydrodynamic lubrication theory. They recommended an applicable and convenient subdomain isoparametric transformation. They took a finite length radial bearing as an example, used eightnode rectangle isoparametric finite element, and obtained the rigid solution and elastic solution under heavy load [11-13]. In recent years, with the emergence of new bearing materials, the elastic modulus of materials such as elastic 
metal-plastic is lower than the metals by one order of magnitude which enables the bearing shell's elastic deformation to have significant effect on oil film thickness [14]. Therefore, the introduction of bearing shell factor into the study of ship dynamic pressure oil film bearing has made the theoretical calculation conform to the actual results. This has significant meaning in the design and fault diagnosis of dynamic pressure oil film bearing of the ships.

\section{ESTABLISH MATHEMATICAL MODEL}

\subsection{The Basic Equation of Hydrodynamic Pressure Lubrication}

The key question of studying dynamic pressure oil film bearing is to solve Reynolds equation. Wherein, the Reynolds equations for infinite width and infinitely narrow bearing already have relatively accurate analytical solutions. However, as the width of actual bearing is finite, so the complete binary flow Reynolds equation must be solved:

$\frac{\partial}{\partial x}\left(\frac{h^{3}}{\eta} \frac{\partial p}{\partial x}\right)+\frac{\partial}{\partial z}\left(\frac{h^{3}}{\eta} \frac{\partial p}{\partial z}\right)=6\left(U_{1}-U_{2}\right) \frac{\partial h}{\partial x}$

In order to let the formula have a compact structure and highlight the role of each relevant factor, dimensionless form is usually adopted for calculation.

$x=r \varphi, z=\lambda \frac{L}{2}, H=\frac{h}{c}, \bar{p}=\frac{p}{p_{0}}$. Set $p_{0}=\frac{6 U \eta r}{c^{2}}$, then the dimensionless form of formula (1) is as follows:

$\frac{\partial}{\partial \varphi}\left(H^{3} \frac{\partial \bar{p}}{\partial \varphi}\right)+\left(\frac{d}{L}\right)^{2} \frac{\partial}{\partial \lambda}\left(H^{3} \frac{\partial \bar{p}}{\partial \lambda}\right)=\frac{\partial H}{\partial \varphi}$

\subsection{Determine the Boundary Conditions}

This article chose Reynolds boundary conditions. The termination point of oil film pressure was at the certain angle $\phi_{2}$ after passing the minimal oil film thickness. Mathematical expression is:

$\varphi=\varphi_{1}=0, \mathrm{p}=1 p a$

$\varphi=\varphi_{2}, \mathrm{p}=1 p a, \frac{d p}{d \varphi}=0$

$\varphi_{2} \leq \varphi \leq 2 \pi, \mathrm{p}=1 p a, \frac{d p}{d \varphi}=0$

\subsection{Establish Coupling Algorithm}

Considering the elastic deformation of oil film bearing, the oil film pressure distribution and elastic deformation distribution of oil film bearing are simultaneous, synchronous and interactional in calculation. Also the two should be solved together. Whereas, when dealing with this kind of problem in the past, oil film pressure was calculated first, then the elastic deformation of oil film bearing under the calculated pressure and finally the effect of elastic deformation on oil film distribution and other lubrication performances of oil film bearing were calculated $[15,16]$. Actually, this calculation method has certain defects as it did not achieve coupling in the real sense.
Solving Reynolds equation by numerical method is an iterative process of solving oil film pressure distribution. If the effect of bearing shell's elastic deformation on the bearing's oil film pressure distribution as well as the interaction of bearing's oil film pressure distribution and bearing shell's elastic interaction are included in each iteration process, the final convergence results can be in better accordance with the actual situation [17, 18]. Based on the above ideas, this article used finite difference method to solve the Reynolds equation of oil film bearing. Meanwhile, finite element method, FEM, was used to solve the elastic deformation of the oil film bearing. Then the two methods were combined to form the coupling algorithm in the real sense.

\subsubsection{Solve Two-Dimensional Reynolds Equation with Difference Method}

$$
\left(\frac{\partial P}{\partial \phi}\right)_{i, j}=\frac{P_{i+\frac{1}{2}, j}-P_{i-\frac{1}{2}, j}}{\Delta \phi} ;\left(\frac{\partial P}{\partial \lambda}\right)_{i, j}=\frac{P_{i, j+\frac{1}{2}}-P_{i, j-\frac{1}{2}}}{\Delta \lambda}
$$

$\frac{\partial}{\partial \phi}\left(H^{3} \frac{\partial P}{\partial \phi}\right)_{i, j}=\frac{\left(H^{3} \frac{\partial P}{\partial \phi}\right)_{i+\frac{1}{2}, j}-\left(H^{3} \frac{\partial P}{\partial \phi}\right)_{i-\frac{1}{2}, j}}{\Delta \phi}$

$=\frac{H_{i+\frac{1}{2}, j}^{3} P_{i+1, j}+H_{i-\frac{1}{2}, j}^{3} P_{i-1, j}-\left(H_{i+\frac{1}{2}, j}^{3}+H_{i-\frac{1}{2}, j}^{3}\right) P_{i, j}}{(\Delta \phi)^{2}}$

$(\Delta \phi)^{2}$

In the same way:

$$
\begin{aligned}
& \frac{\partial}{\partial \lambda}\left(H^{3} \frac{\partial P}{\partial \lambda}\right)_{i, j}=\frac{\left(H^{3} \frac{\partial P}{\partial \lambda}\right)_{i, j+\frac{1}{2}}-\left(H^{3} \frac{\partial P}{\partial \lambda}\right)_{i, j-\frac{1}{2}}}{\Delta \lambda} \\
& =\frac{H_{i, j+\frac{1}{2}}^{3} P_{i, j+1}+H_{i, j-\frac{1}{2}}^{3} P_{i, j-1}-\left(H_{i, j+\frac{1}{2}}^{3}+H_{i, j-\frac{1}{2}}^{3}\right) P_{i, j}}{(\Delta \lambda)^{2}}
\end{aligned}
$$

For item $\frac{\partial H}{\partial \phi}$, we have: $\left(\frac{\partial H}{\partial \phi}\right)_{i, j}=\frac{H_{i+\frac{1}{2}, j}-H_{i-\frac{1}{2}, j}}{\Delta \phi}$

By plugging all the above formulas into two-dimensional Reynolds equation, it can be turned into:

$$
\begin{aligned}
& H_{i+\frac{1}{2}, j}^{3} \cdot P_{i+1, j}+H_{i-\frac{1}{2}, j}^{3} \cdot P_{i-1, j}+\left(\frac{d}{L} \frac{\Delta \phi}{\Delta \lambda}\right)^{2} \cdot H_{i, j+\frac{1}{2}}^{3} \cdot P_{i, j+1} \\
& +\left(\frac{d}{L} \frac{\Delta \phi}{\Delta \lambda}\right)^{2} \cdot H_{i, j-\frac{1}{2}}^{3} \cdot P_{i, j-1} \\
& +\left[H_{i+\frac{1}{2}, j}^{3}+H_{i-\frac{1}{2}, j}^{3}+\left(\frac{d}{L} \frac{\Delta \phi}{\Delta \lambda}\right) \cdot\left(H_{i, j+\frac{1}{2}}^{3}+H_{i, j-\frac{1}{2}}^{3}\right)\right] P_{i, j} \\
& =\Delta \phi \cdot\left(H_{i+\frac{1}{2}, j}-H_{i-\frac{1}{2}, j}\right)
\end{aligned}
$$

Let 


$$
\left\{\begin{array}{l}
A_{i, j}=H_{i+\frac{1}{2}, j}^{3}, \quad B_{i, j}=H_{i-\frac{1}{2}, j}^{3}, \quad C_{i, j}=\left(\frac{d}{L} \frac{\Delta \phi}{\Delta \lambda}\right)^{2} H_{i, j+\frac{1}{2}}^{3}, \\
D_{i, j}=\left(\frac{d}{L} \frac{\Delta \phi}{\Delta \lambda}\right)^{2} H_{i, j-\frac{1}{2}}^{3}, \quad E_{i, j}=A_{i, j}+B_{i, j}+C_{i, j}+D_{i, j}, \\
F_{i, j}=\Delta \phi\left(H_{i+\frac{1}{2}, j}-H_{i-\frac{1}{2}, j}\right)
\end{array}\right.
$$

Then:

$$
A_{i, j} \cdot P_{i+1, j}+B_{i, j} \cdot P_{i-1, j}+C_{i, j} \cdot P_{i, j+1}+D_{i, j} \cdot P_{i, j-1}+E_{i, j} \cdot P_{i, j}=F_{i, j}
$$

The above formula constitutes a group of linear inhomogeneous algebraic equations of $P_{i, j}$ value of $(m-1)(n-1)$ internal nodes, to solve the $P_{i, j}$ value of each node.

\subsubsection{Solve Elastic Deformation with Finite Element Method}

When FEM was used to calculate the elastic deformation of the bearing, a three-dimensional finite element model was adopted. As the thickness of the bearing shell is far less than the bearing shell's perimeter expanded along the circumference, the bearing shell of oil film bearing can be approximately expanded into a rectangle along the circumference. $\mathrm{X}, \mathrm{Y}$, and $\mathrm{Z}$ are the axial direction, circumferential direction and thickness direction of the bearing shell, respectively. Eight-node hexahedron rectangular element was used to discretize the entire model.

$u, \quad v$ and $w$ are the displacement vectors of any point in $\mathrm{x}$, $\mathrm{y}$ and $\mathrm{z}$ direction.

The displacement vector in $\mathrm{x}$ direction can be written as $u=a_{1}+a_{2} x+a_{3} y+a_{4} z+a_{5} x y+a_{6} x z+a_{7} y z+a_{8} x y z$

The displacement value of the 1 st node is assumed as $u_{1}$, and by this analogy, the displacement values of the rest nodes $\left(u_{2} \cdots u_{8}\right)$ are achieved. For an eight-node unit, there are a total of eight formulae written in matrix form as follows:

Let

$$
\begin{aligned}
& N=\left(\begin{array}{l}
N_{1} \\
N_{2} \\
N_{3} \\
N_{4} \\
N_{5} \\
N_{6} \\
N_{7} \\
N_{8}
\end{array}\right)=\left(\begin{array}{c}
1 \\
x \\
y \\
z \\
x y \\
x z \\
y z \\
x y z
\end{array}\right)^{T}\left(\begin{array}{cccccccc}
1 & x_{1} & y_{1} & z_{1} & x_{1} y_{1} & x_{1} z_{1} & y_{1} z_{1} & x_{1} y_{1} z_{1} \\
1 & x_{2} & y_{2} & z_{2} & x_{2} y_{2} & x_{2} z_{2} & y_{2} z_{2} & x_{2} y_{2} z_{2} \\
1 & x_{3} & y_{3} & z_{3} & x_{3} y_{3} & x_{3} z_{3} & y_{3} z_{3} & x_{3} y_{3} z_{3} \\
1 & x_{4} & y_{4} & z_{4} & x_{4} y_{4} & x_{4} z_{4} & y_{4} z_{4} & x_{4} y_{4} z_{4} \\
1 & x_{5} & y_{5} & z_{5} & x_{5} y_{5} & x_{5} z_{5} & y_{5} z_{5} & x_{5} y_{5} z_{5} \\
1 & x_{6} & y_{6} & z_{6} & x_{6} y_{6} & x_{6} z_{6} & y_{6} z_{6} & x_{6} y_{6} z_{6} \\
1 & x_{7} & y_{7} & z_{7} & x_{7} y_{7} & x_{7} z_{7} & y_{7} z_{7} & x_{7} y_{7} z_{7} \\
1 & x_{8} & y_{8} & z_{8} & x_{8} y_{8} & x_{8} z_{8} & y_{8} z_{8} & x_{8} y_{8} z_{8}
\end{array}\right)^{-1} \\
& {\left[\phi_{u}\right]=\left[\begin{array}{llllllll}
u_{1} & u_{2} & u_{3} & u_{4} & u_{5} & u_{6} & u_{7} & u_{8}
\end{array}\right]^{T}}
\end{aligned}
$$

So the displacement vector in $\mathrm{x}$ direction can be expressed as: $u=[N] \cdot\left[\phi_{u}\right]$

By analogy,

the displacement vector in y direction can be expressed as: $v=[N] \cdot\left[\phi_{v}\right]$;

the displacement vector in $\mathrm{z}$ direction can be expressed as: $w=[N] \cdot\left[\phi_{w}\right]$.

$$
\begin{aligned}
\left(\begin{array}{c}
u \\
v \\
w
\end{array}\right)= & {\left[\begin{array}{lllllllll}
N_{1} & \cdots & N_{6} & 0 & \cdots & \cdots & \cdots & \cdots & 0 \\
0 & \cdots & 0 & N_{1} & \cdots & N_{6} & 0 & \cdots & 0 \\
0 & \cdots & \cdots & \cdots & \cdots & 0 & N_{1} & \cdots & N_{6}
\end{array}\right] } \\
& \cdot\left(\begin{array}{lllllllll}
u_{1} & \cdots & u_{6} & v_{1} & \cdots & v_{6} & w_{1} & \cdots & w_{6}
\end{array}\right)^{T}
\end{aligned}
$$

The strain of three-dimensional entity has a total of six components, including three normal strains and three shear strains arranged into vector form as follows:

$(\varepsilon)=\left(\begin{array}{l}\varepsilon_{x} \\ \varepsilon_{y} \\ \varepsilon_{z} \\ \gamma_{x y} \\ \gamma_{y z} \\ \gamma_{z x}\end{array}\right)=\left(\begin{array}{lll}\partial / \partial x & 0 & 0 \\ 0 & \partial / \partial y & 0 \\ 0 & 0 & \partial / \partial z \\ \partial / \partial y & \partial / \partial x & 0 \\ 0 & \partial / \partial z & \partial / \partial y \\ \partial / \partial z & 0 & \partial / \partial x\end{array}\right) \cdot\left(\begin{array}{c}u \\ v \\ w\end{array}\right)$

Matrix $[B] 、[\phi]$ defined as:

$[B]=\left(\begin{array}{lll}\partial / \partial x & 0 & 0 \\ 0 & \partial / \partial y & 0 \\ 0 & 0 & \partial / \partial z \\ \partial / \partial y & \partial / \partial x & 0 \\ 0 & \partial / \partial z & \partial / \partial y \\ \partial / \partial z & 0 & \partial / \partial x\end{array}\right) \cdot\left[\begin{array}{lllllllll}N_{1} & \cdots & N_{6} & 0 & \cdots & \cdots & \cdots & \cdots & 0 \\ 0 & \cdots & 0 & N_{1} & \cdots & N_{6} & 0 & \cdots & 0 \\ 0 & \cdots & \cdots & \cdots & \cdots & 0 & N_{1} & \cdots & N_{6}\end{array}\right]$

$[\phi]=\left[\begin{array}{lll}\phi_{u} & \phi_{v} & \phi_{w}\end{array}\right]$

By the FEM stiffness, matrix of the unit is obtained as: $[K]=\int[B]^{T} \cdot[D] \cdot[B] d V$

Through calculation: $K \delta=\mathrm{p}$, the node's displacement of the overall structure is obtained.

\subsubsection{The Solving Process of Coupling Algorithm}

This article used the coupling algorithm to solve the characteristics of the bearing. First, all the initial values of oil film pressure and the bearing shell's elastic deformation of oil film bearing were set to zero. Meanwhile the initial value of bearing's oil film thickness, which is the oil film thickness in rigid conditions, was calculated. Based on this, centered difference quotient method was used to solve Reynolds equation to obtain a set of pressure distribution. Then, FEM was used to calculate the elastic deformation generated by sliding bearing and bearing shell under the calculated oil film pressure distribution. In the coupling process, elastic deformation generated by bearing shell 
affects the thickness of bearing's oil film in-turn; this is why this elastic deformation was used to correct the oil film thickness. Then, centered difference quotient method was again adopted to calculate the oil film pressure distribution under revised oil film thickness. This iteration is repeated until they converge. The flow-process diagram is as follows:

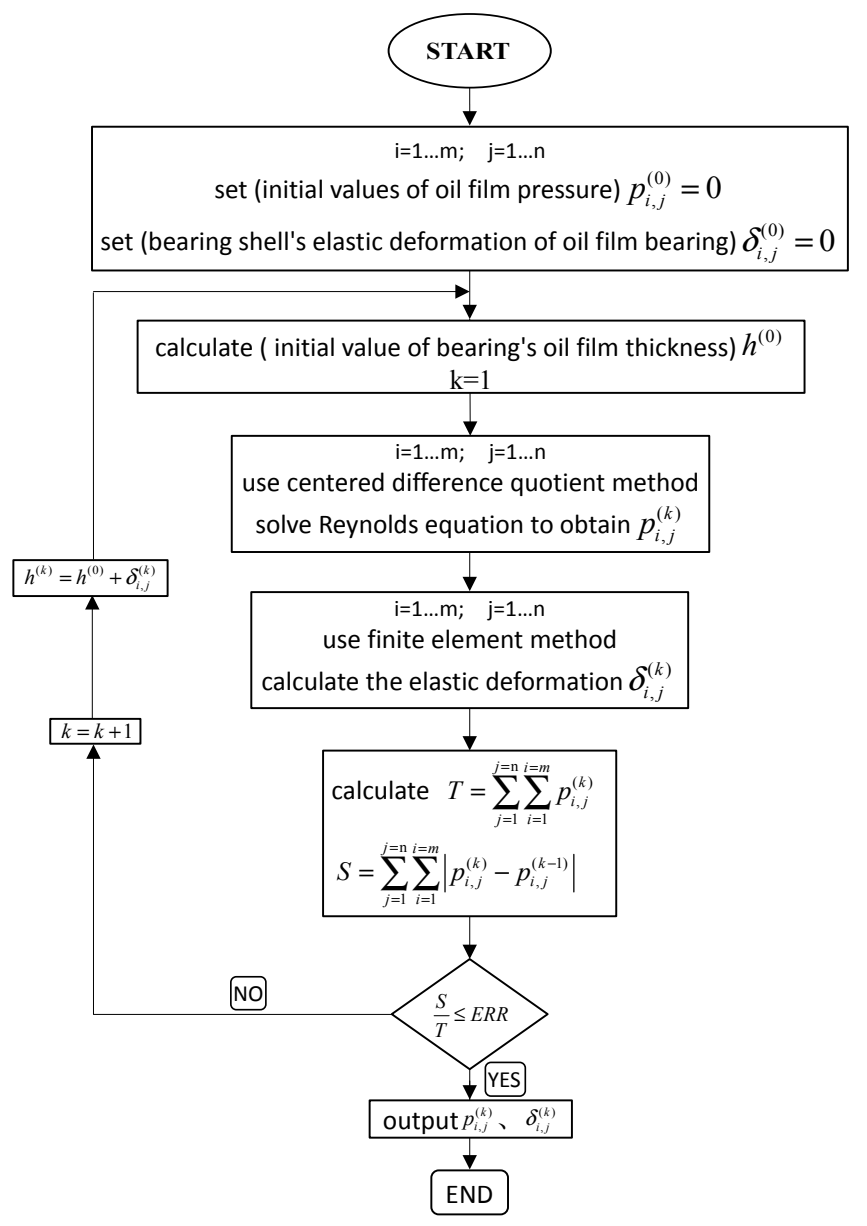

\section{CALCULATION RESULTS AND CONTRASTIVE ANALYSIS}

Based on the proposed mathematical model, an oil film bearing is selected with an actual given parameter (Table 1), and every lubrication performance of oil film bearing is calculated in consideration of bearing shell's elastic deformation. Contrastive analysis of the results is conducted for conditions which do not take elastic deformation into consideration.

\subsection{Oil Film Pressure and Elastic Deformation}

Fig. (1) shows the three dimensional distribution of oil film pressure in considering the bearing shell's elastic deformation. The result basically conformed to the result of conditions which does not take elastic deformation into consideration. Fig. (2) shows the elastic deformation distribution of inner bearing shell surface under the effect of oil film pressure. Positive elastic deformation value indicates that the elastic deformation direction of the inner bearing shell surface was consistent with the acting direction of oil film pressure. The distribution trend of inner bearing shell surface's elastic deformation and dimensionless oil film
Table 1. The specific parameters of dynamic pressure of oil film bearing.

\begin{tabular}{|l|c|}
\hline Journal Diameter (d) & $1.2 \mathrm{~m}$ \\
\hline Inner Diameter of Bearing Shell $\left.\mathbf{( d}_{\mathbf{i}}\right)$ & $1.2014 \mathrm{~m}$ \\
\hline Outer Diameter of Bearing Shell $\left.\mathbf{( d}_{\mathbf{0}}\right)$ & $1.25 \mathrm{~m}$ \\
\hline Linear Velocity of Bearing Journal $(\mathbf{U})$ & $1.2566 \mathrm{~m} / \mathrm{s}$ \\
\hline Width-Radius Ratio $(\mathbf{L} / \mathbf{D})$ & 1 \\
\hline Relative Clearance $\left(\mathbf{R}_{\mathbf{c}}\right)$ & 0.0012 \\
\hline Bearing Eccentricity (e) & 0.8 \\
\hline Dynamic Viscosity of Lubrication Oil $(\boldsymbol{\eta})$ & $0.025 \mathrm{Pa.s}$ \\
\hline $\begin{array}{l}\text { Elastic Modulus of Bearing Shell Material } \\
(\mathbf{E})\end{array}$ & $3 \times 10^{11} \mathrm{~N} / \mathrm{m}^{2}$ \\
\hline
\end{tabular}

pressure was consistent. The maximum elastic deformation of inner bearing shell surface and the oil film pressure can be obtained in the same position. From this, it can be inferred that oil film pressure is the main force of elastic deformation of bearing shell.

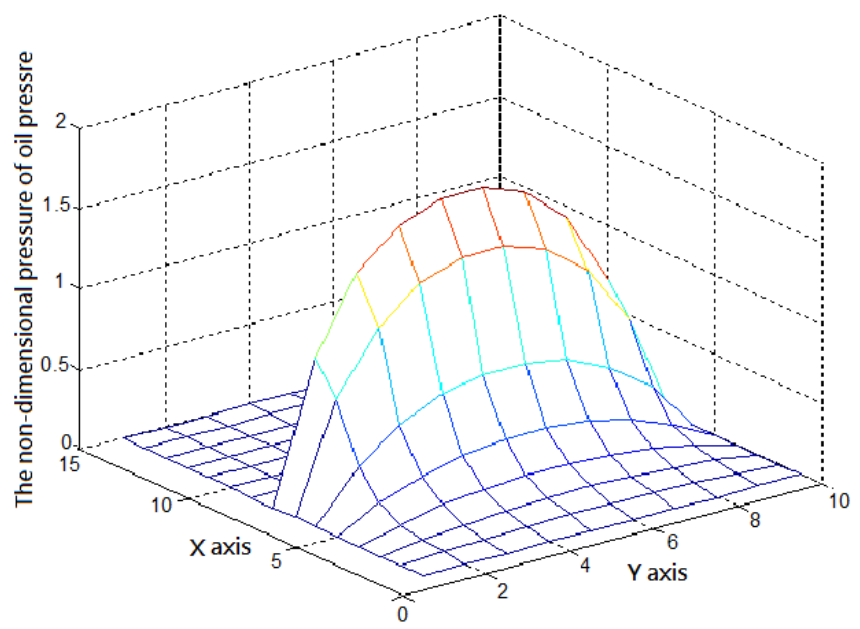

Fig. (1). Dimensionless oil film pressure.

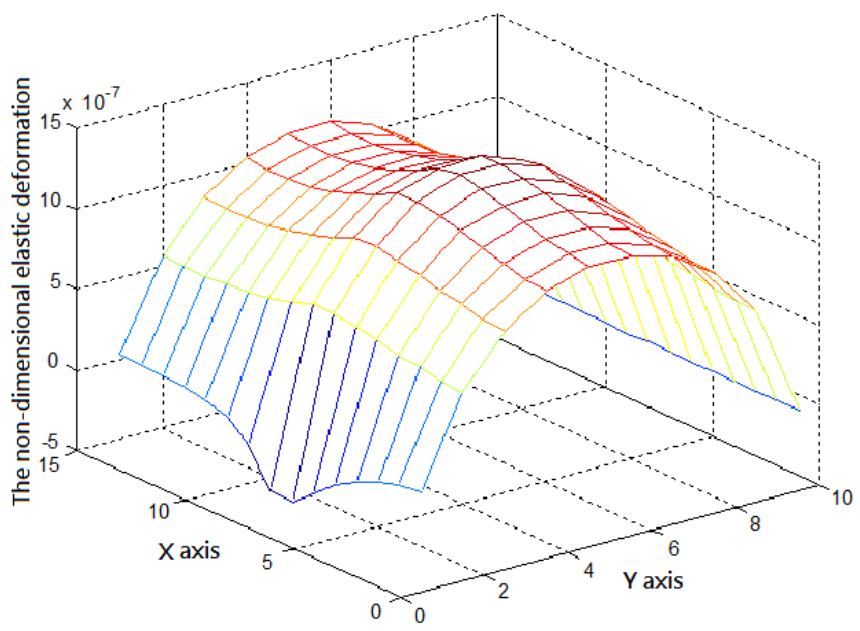

Fig. (2). Elastic deformation distribution diagram of the bearing shell's inner surface. 


\subsection{The Relationship Between Elastic Deformation and Oil Film Pressure Distribution}

Eccentricity is an important indicator of dynamic pressure oil film bearing. In order to further study the effect of bearing shell's elastic deformation on the performance of oil film bearing under different eccentricities, the circumferential and axial dimensionless oil film pressure distribution are calculated with or without consideration of elastic deformation.

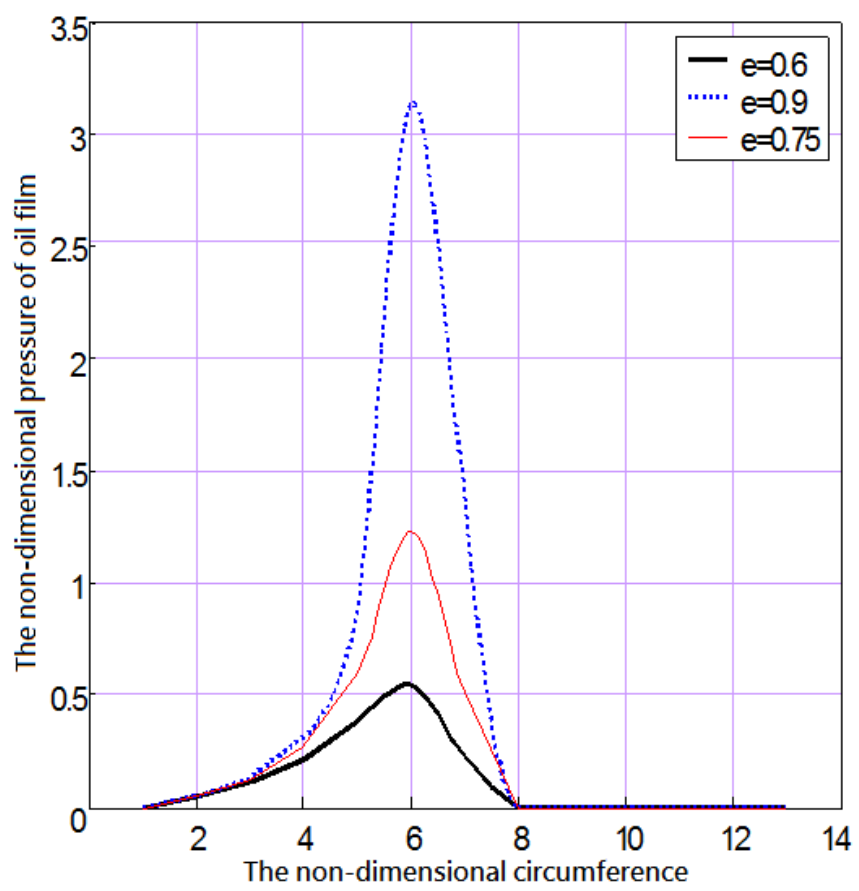

Fig. (3). Circumferential dimensionless (without consideration of elastic deformation).

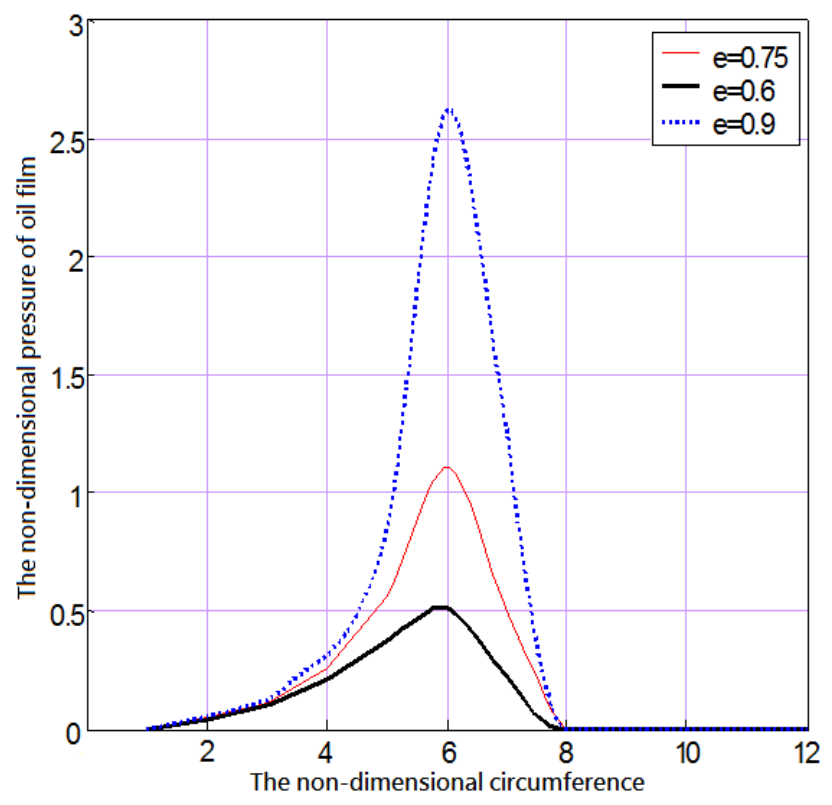

Fig. (4). Circumferential dimensionless (with consideration of elastic deformation).

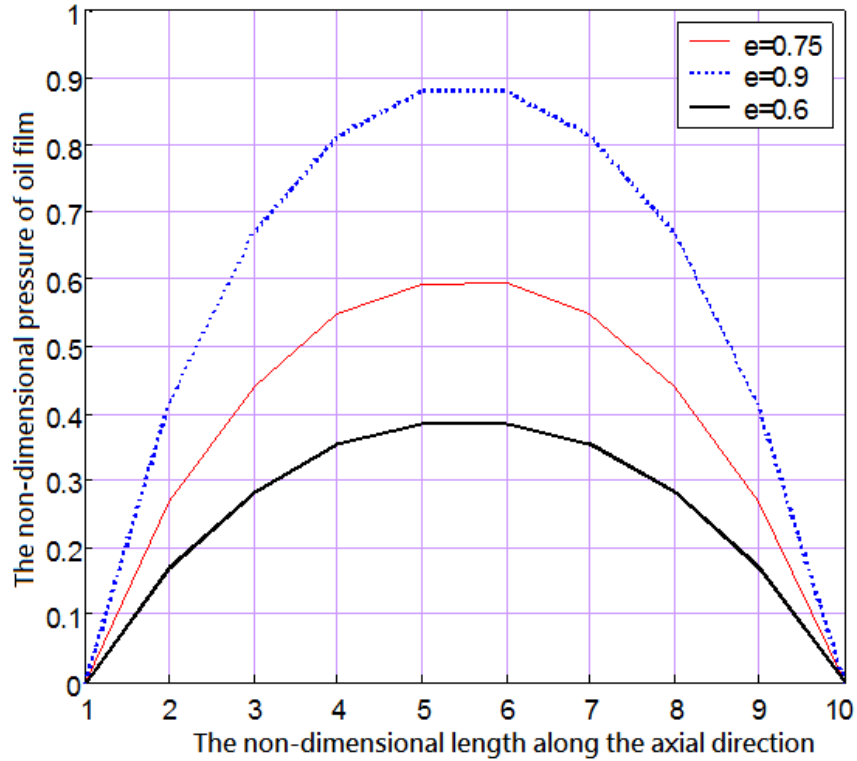

Fig. (5). Axial dimensionless (without consideration of elastic deformation).

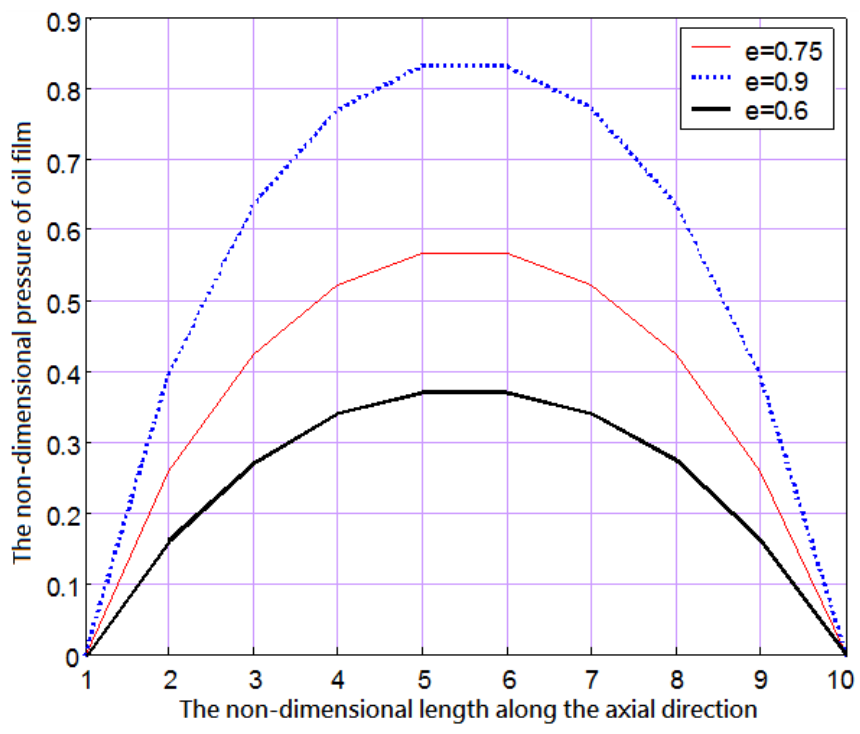

Fig. (6). Axial dimensionless (with consideration of elastic deformation).

Figs. (1, 2) respectively show the circumferential dimensionless oil film pressure distribution with or without consideration of elastic deformation. When the eccentricity is the same, the circumferential oil film pressure distribution trends are roughly the same. But when considering elastic deformation, the peak value of oil film pressure is smaller than when the elastic deformation is not considered. This is mainly because the elastic deformation of bearing shell enlarges the clearance between the inner bearing shell surface and outer journal surface, which reduces the wedging actions of bearing clearance. And with the increase of eccentricity, the difference of circumferential oil film pressure peak values of the two cases becomes greater. Figs. $(3,4)$ represent the axial oil film pressure distribution of the two 
Table 2. Oil film bearing capacity changing with eccentricity.

\begin{tabular}{|c|c|c|c|}
\hline Eccentricity & $\begin{array}{c}\text { Bearing Capacity of Oil Film } \\
\text { (without Consideration of Deformation) }\end{array}$ & $\begin{array}{c}\text { Bearing Capacity of Oil Film } \\
\text { (with Consideration of Deformation) }\end{array}$ & Change Rate (\%) \\
\hline \hline 0.1 & 0.105 & 0.104 & -0.196 \\
\hline 0.2 & 0.198 & 0.294 & $-1.01 \%$ \\
\hline 0.3 & 0.297 & 0.392 & $-1.01 \%$ \\
\hline 0.4 & 0.398 & 0.493 & $-1.51 \%$ \\
\hline 0.5 & 0.501 & 0.878 & $-1.60 \%$ \\
\hline 0.6 & 0.896 & 1.257 & $-2.01 \%$ \\
\hline 0.7 & 1.289 & 1.525 & $-2.48 \%$ \\
\hline 0.8 & 1.601 & 3.115 & $-4.75 \%$ \\
\hline 0.9 & 4.701 & 14.213 & $-33.74 \%$ \\
\hline 0.95 & 27.025 & & $-47.41 \%$ \\
\hline
\end{tabular}

cases, and the characteristics are the same with circumferential ones. That is, elastic deformation does not change oil film distribution, but it changes the peak value of oil film pressure; the greater the eccentricity, the greater the pressure difference.

\subsection{The Relationship Between Elastic Deformation and Bearing Capacity of Oil Film}

The bearing capacity of dynamic pressure oil film is another important feature of the bearing. Therefore, this article also studied the effect of elastic deformation on the bearing capacity of oil film.

As can be seen from Table 2 , the oil film bearing capacities of rigid bearing and bearing considering deformation, all increased with the increase in eccentricity. Negative change rate value indicates that the existence of elastic deformation makes the oil film bearing capacity decline under the same eccentricity. When the eccentricity is small, the effect of elastic deformation on the oil film bearing capacity is small. While with the increase in eccentricity, elastic deformation reduces the bearing's bearing capacity significantly. Taking eccentricity 0.95 for example, the oil film bearing capacity of bearing with elastic deformation considered has fallen by $47.41 \%$ when compared to that of rigid bearing. So when designing and checking the bearings, attention must be paid to the reduction effect of deformation on oil film bearing capacity. Especially for circumstances under large eccentricities, the effect of elastic deformation on oil film bearing capacity cannot be ignored.

\section{CONCLUSION}

i. Oil film pressure mainly functions on the elastic deformation of ship bearing shell. The elastic deformation direction of the inner bearing shell surface is consistent with the acting direction of oil film pressure and the maximum deformation and oil film pressure can be obtained in the same position

ii. Elastic deformation does not change the circumferential and axial pressure distribution of ship oil film but it affects the peak value of the pressure. Under the same eccentricity, the peak value of oil film pressure with consideration of elastic deformation is lower than the ones without elastic deformation consideration. With the increase in eccentricity, the pressure difference between the two becomes greater.

iii. Elastic deformation affects the bearing capacity of ship bearing. When the eccentricity is small, the effect is not obvious. While with the increase in eccentricity, elastic deformation significantly reduces the bearing capacity of the bearing.

\section{CONFLICT OF INTEREST}

The authors confirm that this article content has no conflict of interest.

\section{ACKNOWLEDGEMENTS}

Support by the fundamental research funds for the central universities (3132014318).

\section{REFERENCES}

[1] L. Ling, W. Lihong, "Design analysis of oil film bearing hydrodynamic lubrication technology", CFHI Technol., vol. 4, pp. 31-32, 2008.

[2] O. Reynolds, "On the theory of lubrication and its application to Mr Beauchamps Tower's Experiments, Including an experimental determination of the viscosity of olive oil", Philos. Trans. R Soc., Lond., vol. 177, pp. 157-234, 1886.

[3] Z. Yun, L. Jian-ting, Y. Jian-xi, "Analysis on load capacity of hydrodynamic kelmet with harmonic waves", Bearing, vol. 5, pp. 19-21, 2007.

[4] Y. Jian-xi, Fan Hong-chao, "Analysis and comparison for carrying capacity of kelmet", Bearing, vol. 8, pp. 25-6, 2004.

[5] H. Qing-xue, W. Jian-mei, L. Yu-gui "The numeric analysis on elastrohydrodynamic problem of oil-film bearing under heavy loads", J. Taiyuan Univ. Sci. Technolo., vol. 1, pp. 39-42, 2004.

[6] C. Shao-qi, C. Han, "The numerical solution of lubricationmechanical equation for heavy-loaded journal bearings", $J$ Xi-an Jiaotong Univ., vol. 16, no. 2, pp.119-25, 1982.

[7] Z. Lin, and H. Qingxue, "Analysis of oil-film flow field for low speed and heavy load oil-film bearing", Shanxi Metall., vol. 23, no. 3, pp.1-3, 2010.

[8] H.D. Conway, and H.C. Lee, "A generalized reynolds equation for fluid film lubrication”, Int. J. Mech. Sci., vol. 4, no. 1, pp. 159-70, 1962.

[9] S. Da-cheng, "A parametric study of stress sources in journal bearings", Int. J. Mechan. Sci., vol. 38, no. 8, pp.1001-15, 1996. 
[10] S. Zhi-wen, "BP network model for nonlinear oil-film force on hydrodynamic bearing", Tribology, vol. 22, no. 5, pp. $226-31$, 2002.

[11] Z. Wei, C. Min, and T. Shui-guang, "Numerical simulation of deformation and stress in sliding bearing considering oil film lubrication", J. Zhejiang Univ,, (Eng Sci), vol. 46, no. 7, pp. 122732, 2012.

[12] Z. Yong, M. Sen-quan, and W. Jia, "Coupling algorithm for EHL of journal bearings", Bearing, vol. 4, pp. 11-15, 2010.

[13] C. Shaoqi, G. Hong, and L. Ruizhen, "Research on the elastohydrodynamic lubrication dynamic characteristics of super heavy load hybrid bearing considering the dynamic deformation of journal and bearing tile", Lubrica. Eng., vol. 32, pp. 5-7, 2007.
[14] Y. Shu-yan, W. Hai-feng, and G. Fen, "Influence of grooved surfaces on the film thickness of hydrodynamic lubrication", Tribology, vol. 31, no. 3, pp. 283-8, 2011.

[15] Q. Chuan, "The pressure distribution calculation of hydrodynamic oil film of bearing with uncertain solution domain", Modern Manufact. Eng., vol. 12, pp. 99-103, 2013.

[16] C. Ling-shan, Z. Ji-hua, and T. Guo-lan, "An analysis of the lubricating condition for the elastic deformation on dynamically loaded journal bearings", Lubricat. Eng., vol. 16(1), 65-6, 2003.

[17] L. Xing-xing, M. Zai-qiang, and M. Guang, "Oil film force model of tilting pad bearing and its characteristic analysis", Noise Vib. Control, 33, no. 4, pp. 59-63, 2013.

[18] S. Yunhui, and M. Xizhi, "Influence of elastic deformation on ball mill bearing”, Lubricat. Eng., vol. 36, no. 1, pp. 65-9, 2011.

Received: September 10, 2014

Revised: November 5, 2014

Accepted: November 5, 2014

(C) Liu and Li; Licensee Bentham Open

This is an open access article licensed under the terms of the Creative Commons Attribution Non-Commercial License (http://creativecommons.org/licenses/ by-nc/4.0/) which permits unrestricted, non-commercial use, distribution and reproduction in any medium, provided the work is properly cited. 